\title{
Noninvasive Alternatives to Liver Biopsy
}

\author{
Ludmila Viksna $^{1}$ et al. ${ }^{*}$ \\ ${ }^{1}$ Riga Stradins University, \\ Latvia
}

\section{Introduction}

During the past 60 years the role and importance of liver biopsy have changed. In 1950s the introduction of liver puncture biopsy was absolute innovation, e.g. in Latvia, and had an invaluable significance. The possibility to compare and/or oppose alterations of liver structure and liver function was achieved and it caused the information explosion. The spectrum of morphological research included investigations of liver tissue damage on different levels that explained the mechanisms of biochemically detected cytolysis and cholestasis syndrome, fibrosis and liver cirrhosis development. Relatively, in least degree the morphological phenomena of apoptosis and its role in acute and chronic liver diseases were examined.

Frequently conventional liver function tests are limited to quantifying hepatic function. Despite major progress in the diagnostics and therapy of liver diseases of different etiologies, the assessment of liver function continues to present a major clinical problem. Most of liver function tests are not sufficiently specific and do not accurately predict liver failure and outcome of it.

Liver biopsy is an essential part of the diagnostics and follow-up of many liver diseases giving clinically important information as well as scientific data. At present, it is the most specific test to assess the nature and severity of liver damage (Bravo et al., 2001). However, the role of liver biopsy in the evolution of medical science is dynamic. It became possible with the development of methods able to bring sufficient amount of liver tissue as well as to ensure the safety of the procedure itself. The methods used to obtain liver tissue include transcutaneous needle biopsy and transvenous approach via jugular or femoral vein. Occasionally, liver can be biopsied during laparoscopy or open abdominal surgery. Aseptics and antiseptics are of importance. There is an obvious necessity to ensure the monitoring of the patient and control of possible albeit rare complications. It seems reasonable to expect further developments in the field of liver morphology that might include both in-depth studies of tissue (Dioguardi et al., 2008) as well as elaboration of novel, completely different diagnostic methods.

The indications for liver biopsy include 1) the grading and staging of chronic viral hepatitis, alcohol-related liver damage, non-alcoholic steatohepatitis and autoimmune hepatitis; 2)

\footnotetext{
*Valentina Sondore² ${ }^{2}$ Jāzeps Keiss², Agita Jeruma², Pēteris Prieditis'1 ${ }^{1}$ Ilze Strumfa1, Arturs Sochnevs' ${ }^{1}$ and Baiba Rozentale ${ }^{2}$.

1 Riga Stradins University, Latvia,

2 State agency "Infectology Center of Latvia”, Latvia.
} 
evaluation of hemochromatosis and Wilson's disease; 3) diagnostics of biliary diseases; 4) evaluation of patient with abnormal biochemical liver tests; 5) evaluation of medication toxicity; 6) diagnosis of focal liver lesion; 7) evaluation of liver transplant; 8) evaluation of patient with fever of unknown origin (Bravo et al., 2001). Liver biopsy ensure accurate diagnosis in $90 \%$ of patients with abnormal biochemical liver tests (Hultcrantz\&Gabrielsson, 1993) and is informative in transplant patients revealing rejection, recurrence of primary disease, drug toxicity and other causes of liver damage (Brown et al., 2000).

The general limitations of liver biopsy represent the risk of complications (Poynard et al., 2004), sampling error (Poynard et al., 2004; Skripenova et al., 2007) and inter- and intraobserver variability (Poynard et al., 2004). However, the risk of serious complications is low (Shiha et al., 2009) - 3 per 1000 (Poynard et al., 2004), and the general risk of complications is estimated as 1\% (Standish et al., 2006). The described risk of mortality has been between $0.1 \%-0.01 \%$ (Standish et al., 2006). The variability can be reduced by scoring systems, and sampling error can be partially limited by keeping the standards. Namely, liver biopsy can be considered representative if it contains at least 11 portal fields or measures at least $1 \mathrm{~cm}$ (Skripenova et al., 2007). If the tissue fragment is markedly less than $1 \mathrm{~cm}$, immediate rebiopsy can be performed.

Liver biopsy allows to perform visual examination of tissue structure. To ensure this, the logistics is mostly routine, not placing high requirements. The biopsied tissues are fixed in formalin and embedded in the paraplast. The paraffin blocks and stained sections can be archived thus providing several benefits. The biopsy can be re-evaluated and/or sent for second opinion. The second opinion can be obtained faster by application of full slide scanning and exchange of electronic files. The tissues can be later subjected to any novel examination methods in accordance with the development of medical science and practice. Scientific studies can also benefit from those materials, especially in large medical centres. The turnover time for liver biopsy is reasonable - 24 hours for routine logistics or 4 hours using fast processing.

The informativity of biopsy is highly dependent on the applied protocol of visualisation methods. The routine protocol could include haematoxylin-eozin (Gamble\&Wilson, 2002), PAS (Totty, 2002), Masson's trichrome (Jones, 2002) and Perls' stain (Churukian, 2002) although modifications can definitely exist. Reticulin stain (Jones, 2002) can be advised. Stains for Wilson's disease can be applied to selected cases (Churukian, 2002). Immunohistochemistry for cytokeratins 7 and / or 19 helps to highlight bile ducts and is very useful in the assessment of general morphology, bile duct damage, ductopenia, ductular reaction. Viral antigens should be sought for (Desmet\&Rosai, 2004). The differential diagnostics of focal lesions involves the need to differentiate between benign and malignant lesion, primary and metastatic malignancy including the complex question of identifying the origin of cancer of unknown primary. Thus, wide spectrum immunohistochemistry and search for chromosomal translocations are the requirements for diagnostics.

Further, we will describe in short the informativity of biopsy in different clinical situations, with the emphasis on the limitations.

The application of serologic and virologic examination has mostly replaced the use of biopsy for the diagnostics of acute viral hepatitis. If biopsy is performed, the type and degree of hepatocellular damage, the inflammatory acivity and presence or absence of regeneration can be assessed (Desmet\&Rosai, 2004). Predominance of lobular parenchymal lesions is 
characteristic. The alternative diagnoses or combined liver lesion can be revealed in biopsy. It can be clinically reasonable to perform liver biopsy in order to differentiate between acute and chronic hepatitis. If marked fibrosis is present the morphological diagnosis is straightforward. However, this situation can also represent one of the limits of morphological diagnosis as the portal infiltrate in acute hepatitis may be marked and cause some degree of damage to limiting plate thus resembling chronic active hepatitis. In turn, some cases of chronic hepatitis show only mild changes. In case of severe acute hepatitis, the biopsy might reveal bridging or submassive necrosis. However, the condition of the patient can preclude the biopsy in such situations. The representativity of biopsy can be the limiting factor in the evaluation of submassive liver necrosis due to focality of lesions.

In case of chronic hepatitis, semiquantitative scoring systems provide useful prognostic information, improve the consistency of reporting the disease activity and stage and ensure acceptable intra- and interobserver variability. The examples of such systems include the Histological Activity (HAI) index or Knodell index (Knodell et al., 1981), the Scheuer scoring system (Scheuer, 1991), the modified HAI by Ishak (Ishak et al., 1995) and METAVIR system (Bedossa\&Poynard, 1996). The extent of liver fibrosis can be evaluated directly in the biopsy. This assessment is highly accurate in cirrhosis, bridging fibrosis and portal fibrosis and yields clinically unexpected data only occasionally. Liver biopsy is the procedure of choice to assess the amount of fibrosis in the tissue (Shiha et al., 2009). The biopsy allows assessing even slight tissue damage. Even mild hepatitis can progress as reflected by increasing level of fibrosis in repeated liver biopsies (Ryder et al., 2004). Liver steatosis is frequently found in chronic hepatitis patients and can contribute to the elevation of transaminases level in blood. The degree and type of liver steatosis can be assessed separately from the necroinflammatory activity. Biopsy can also reveal combined liver damage. The limitations of biopsy in the diagnostics of chronic viral hepatitis are represented by the lack of specific morphologic changes, particularly regarding chronic viral hepatitis $\mathrm{C}$. Thus, the biopsy must be used in conjunction with serologic and virologic data.

Liver biopsy can be used for the diagnosis of steatosis and steatohepatitis. Quantitative evaluation is possible for steatosis and fibrosis. Although fat stains can be used high quality routine histological slides stained with haematoxylin and eozin and PAS usually ensure the diagnosis. The limitations are caused by inability to distinguish between non-alcoholic steatohepatitis and alcohol - related hepatitis in abstaining patient.

Liver biopsy is considered important in establishing the diagnosis of autoimmune hepatitis (Oo et al., 2010). The information about features typical for autoimmune hepatitis is helpful as reflected by inclusion of these data in the diagnostic criteria. The absence of biliary abnormalities or steatosis is also of importance helping to exclude alternative diagnoses. The effect of immunosuppresion can be predicted (Feld, 2005) and monitored by biopsy (Oo et al, 2010). Biopsy is recommended before treatment withdrawal (Carpenter\&Czaja, 2002; Montano-Loza et al, 2007; Czaja\&Carpenter, 2003). Due to lack of specifity and possibility of plasma cell paucity in autoimmune hepatitis, the serologic data must be evaluated together with the biopsy.

Examination of liver biopsy for biliary diseases represents a complex problem. The most common questions target primary sclerosing cholangitis and primary biliary cirrhosis. Primary sclerosing cholangitis is a chronic cholestatic liver disease that typically affects young and middle-aged men, frequently suffering from inflammatory bowel disease (Silveira\&Lindor, 2008a, 2008b). Although the disease is rare, it is among frequent 
indications for liver transplantation in Europe and USA, and is dangerous for the increased risk of cholangiocarcinoma. The evaluation of liver biopsy for primary sclerosing cholangitis can both bring information and face problems. Primary sclerosing cholangitis is characterised by loss of medium and large-sized bile ducts. The fibro-obliterative lesions and lack of bile duct in the portal area adjacent to large artery and vein are characteristic. However, ducts of such size are not typically captured in a percutaneous liver biopsy. The concentric periductal fibrosis is characteristic but present in less than $15 \%$ of patients. However, the evaluation of autoantibodies is also not very helpful thus increasing the role of biopsy.

The primary biliary cirrhosis (Hohenester et al., 2009; Kumagi\&Heathcote, 2008) is an immune-mediated chronic progressive inflammatory liver disease characterised by the destruction of small portal bile ducts leading to progressive cholestasis, fibrosis and cirrhosis. Serum antimitochondrial autoantibodies are highly characteristic. Histologically, biliary duct damage and ductopenia are typical. Biopsy is not mandatory, but can be helpful in revealing typical picture, excluding other causes of liver damage and providing stage information.

Hereditary haemochromatosis, a group of inherited disorders that result in progressive iron overload, occurs mostly due to mutations in the HFE gene (Clark et al., 2010). The tests are available to reveal the two clinically relevant mutations C282Y and H63D. However, the penetrance of the disease seems to be low: $28.4 \%$ for males and $1.2 \%$ in females homozygous for C282Y (Clark et al., 2010). Liver biopsy can determine the severity of liver disease; reveal other causes and HFE-mutation negative hemochromatosis.

In case of Wilson's disease, liver biopsy can be implemented in the primary diagnostic work-up. As clinically the course of fibrosis has been found difficult to follow, repeated biopsies are advocated for monitoring (Yokoyama et al., 2010).

In addition, liver biopsy is valuable in the evaluation of focal liver damage including the important and complex question of tumour diagnostics and differential diagnostics. Liver cell tumours and tumour-like lesions represent a wide diagnostic area, including focal nodular hyperplasia, liver cell adenoma, hepatocellular carcinoma, hepatoblastoma, bile duct tumours, epithelioid hemangioendothelioma and other lesions. In the diagnostics of hepatocellular carcinoma, the sensitivity and specifity of liver biopsy is $96 \%$ and $95 \%$, correspondingly (Bialecki\&Bisceglie, 2005). In contrast, the application of other methods can result in false-positive diagnosis with the rate as high as 33\% (Hayashi et al., 2004). In case of malignancy, metastasis should always be considered. The implementation of immunohistochemistry has resulted in higher diagnostic yield of liver biopsy for neoplastic lesions. The identification of the primary origin of metastatic tumours can be reached in a fraction of cases. Inflammatory focal lesions as echinococcosis or liver abscess can be diagnosed reliably.

As shown, liver biopsy is used and should be used as a part of the complex examination for the analysis of the etiology, activity and extent of diffuse and focal liver damage as well as assessment of the treatment results.

Liver biopsy is an invasive method, there are potential adverse effects and complications. Certain precautions and means minimize the risks of adverse events. Biopsy conducted by a trained physician, use of only a limited number of passes and ultrasound quidance can significantly decrease the risk of complications, thereby enhancing the safety of biopsy (Bedossa\&Carrat, 2009). 
The main drawbacks (Bedossa, 2009; Reddy\&Schiff, 2002; Rousselet et al., 2005; Colli\&Fraqeulli, 2009) of liver biopsy as a diagnostic procedure lie in sampling and observation errors. Observer variation is a potential limitation of biopsy that is related to the discordance between pathologists in biopsy interpreation.

The main alternatives to liver biopsy that have been developed in the past 10 years are based on two very different concepts: serum markers and liver stiffness (Manning\&Afdhal, 2008). These are noninvasive procedures.

Biochemical marker combinations are being developed as alternatives to liver biopsy in patients with liver diseases, especially with chronic liver diseases. Noninvasive tests are being developed to replace liver biopsy, and thus avoid the risk of biopsy-related adverse events. Noninvasive tests also have the potential to avoid limitations of liver biopsy including the risk of sampling errors and inter- and intra-pathologist variability.

Although clinicians already use liver biopsy substitutes - surrogate markers in their practices, offers are waiting for more valid tests (Mehta et al., 2009), especially for staging fibrosis and apoptosis identification and confirmation.

Fibrosis is not an autonomous feature, but rather a tissue lesion resulting from other pathologic mechanisms such as inflammatory, degenerative or dystrophic processes leading to other pathologic mechanisms such as hepatocellular carcinoma and portal hypertension.

The physiological process of apoptosis (programmed cell death) can be transformed into a pathological process, which can stimulate hepatic fibrosis, e.g. in hepatitis C, or can contribute to treatment failure (Schinoni et al., 2006). Over the last years, the importance of apoptosis for the pathogenesis of various diseases has been extensively investigated. Apoptosis is a greek term that means "the fall of the old leaves of the autumn trees". This term describes the process by which undesirable, damaged old cells are eliminated from multicellular organisms.

Apoptosis differs from cellular necrosis, because it is actively controlled, and the membrane integrity is maintained, avoiding extravasation of intracellular material and an inflammatory response. In order to discover the probable mechanisms by which hepatitis viruses and other agents perpetuate in the liver, apoptosis in liver disorders should be investigated. Apoptosis is the first step in hepatic lesions, and fibrosis is the final response of hepatic stellate cells to this process. There may be a direct relationship between these two processes.

Apoptosis and cell necrosis can be differentiated by morphology. However, liver diseases are often accompanied by a combination of both processes, so that there is mostly no clear borderline. Apoptosis assessment is still not frequent in liver biopsy. At the same time several apoptosis biochemical markers in blood are available at present (cytochrome C, cytokeratin-18 neoepitopes etc.), but are not widely used in the practice.

Fibrosis is a consequence of the necroinflammatory process. The process of fibrogenesis results in an increase in the extracellular matrix of: 1) collagen, 2) glycoproteins and 3) proteoglycans (e.g. hyaluronic acid).

Fibrotic status is usually assessed by liver biopsy, which has numerous disadvantages (Bottero et al., 2009), therefore prompting the development of several noninvasive methods for assessing fibrosis. However, the etiology of liver disease and the existence of co-morbidities impact the performance of non-invasive markers and cut-off values (Bottero et al., 2009).

Liver biopsy is currently the gold standard for assessment of liver fibrosis, yet it faces competition from non-invasive markers, which are easier to use, more acceptable to patient 
and repeatable over time. Besides, biopsy sample is usually too small to diagnose the disease accurately and diagnostic opinions often differ among pathologists (Rousselet et al., 2005). As a result, a morphological examination does not always provide an accurate diagnosis. Recently, blood hyaluronic acid has been available for the assessment of liver fibrosis as a rapid and less invasive method.

The specific course of disease might be explained also by the diverse immunogenetic backgrounds of the individual patient. The host ability to react to viral antigens has often been associated with the human leukocyte antigen (HLA), mainly HLA class II antigens. Many studies suggest that the cellular immune response, e.g. to $\mathrm{HCV}$, particularly the $\mathrm{T}$ helper (Th) lymphocyte response, plays a crucial role. The cell-receptors recognize only peptides bound to HLA class II molecules. Polymorphisms due to amino acid substitutions at specific positions may intervene within the HLA class II molecule and interact with both the peptide and T-cell-receptor; therefore, the HLA type characterizing each individual may influence the subject's immune response to particular pathogens. Certain HLA alleles have been shown to influence the outcome of other chronic viral infections, and a few recent studies have examined class II HLA alleles in the context of HCV clearance. The present study, which considers the relationship between HCV and HLA class II antigens from the locus DRB1* of view, aimed to investigate whether diferences of HLA class II antigens exist among HCV - infected patients with respect to healthy controls. The possibility that these antigens are associated with resistance or susceptibility to chronic HCV infection was also considered. The HLA class III human leukocyte antigens (DRB1*) are central to the host immune response and thus are ideal candidate genes to investigate for associations with HCV outcomes. During the study we investigated whether human leukocyte antigen (HLADRB1) alleles were associated with the response to PEG-interferon+Ribavirin (combined therapy) and Realdiron therapy in patients with chronic hepatitis C.

Our aim was to identify the new non-invasive methods to be used for the assessment of liver function in acute and chronic liver diseases and to evaluate the clinical diagnostic and prognostic accuracy of these methods, including immunogenetic methods, to cover advantages and disadvantages of noninvasive alternatives to liver biopsy, and to share experience and impressions accumulated in area of hepatology.

\section{Materials and methods}

During the process of apoptosis the sequential activation of caspases (they all are proteases that cleave proteins at aspartic acid residue) creates an expanding cascade of proteolytic activity which leads to digestion of structural proteins in cytoplasm and generates, e.g. apoptotic cytokeratin 18 (CK-18) neoepitopes.

To define the role of apoptosis in the development of acute and chronic HBV and HCV infection, the quantitative detection of serum CK-18 neoepitope was performed by using noninvasive method for caspase-generated CK-18 fragments determination (M30Apoptosense ${ }^{\circledR}$, ELISA kit, PEVIVA, Sweden) in 11 patients with acute hepatitis B, 14 - with acute hepatitis C, 132 - with chronic hepatitis C and, for comparison, in 23 patients with acute alcoholic hepatitis, all treated in the Infectology Center of Latvia.

The mitochondrial pathway involvement in the process of apoptosis was evaluated by determination of serum cytochrome C according to "Human cytochrome C ELISA", Bender MedSystems (Austria) in 129 patients with chronic hepatitis C, in 12 patients with acute hepatitis B and in 29 patients with acute alcoholic hepatitis. 
Serum hyaluronic acid (HA) as a potential marker of fibrosis evolution was measured by ELISA (Corgenix Inc., Colorado, USA) according to description of manufacturer in 16 patients with acute hepatitis B, 9 - with acute hepatitis C, 22 - with acute alcoholic hepatitis and 132 patients with chronic hepatitis $C$.

The study was conducted in compliance with the Declaration of Helsinki and in accordance with Good Clinical Practice guidelines and local regulations and was approved the Ethics Committee of Riga Stradins University (Riga, Latvia).

Diagnosis was based on modern immunochemical hepatitis marker assays and clinical, biochemical and morphological findings. Results were expressed as means \pm SE. For the comparison of two groups the unpaired Student's t-test was used; $\mathrm{p} \geq 0.05 \%$ was considered significant.

168 patients were enrolled in immunogenomic study and divided into four groups. Group A included 59 patients with HCV infection, treated with PEG-interferon + Ribavirin. Group B consisted of 45 patients with $\mathrm{HCV}$ infection and the same treatment regimen, but ineffective. Group C consisted of 30 patients with HCV infection (effective Realdiron therapy). Group D included 34 patients with HCV infection treated with Realdiron (non-responders). In group E, 100 healthy donors were included as the control group.

HLA typing low-resolution for HLA- DRB1* was performed by polymerase chain reaction (PCR) with amplification using sequence-specific primers (SSP). PCR products were separated on $3 \%$ agarose, the amplified bands were visualized, and the DRB1 type was deduced.

The distribution of HLA-DRB1* genes in all five groups (A, B, C, D and E controls) was compared using the chi-squared test with Yates' correction or Fisher's Exact. Odd ratios (OR) were calculated according to the Woolf's formula. All reported p-values were compared to a level of significance set to 0.05 .

\section{Results and discussion}

Performed studies showed very high serum level of CK-18 neoepitope in patients with acute hepatitis B $(1362.3 \pm 108.9 \mathrm{U} / \mathrm{L})$, that is higher than in patients with alcoholic hepatitis $(1003.9 \pm 104.3 \mathrm{U} / \mathrm{L} ; 0.02<\mathrm{p}<0.05)$. CK-18 neoepitope concentration in acute hepatitis $\mathrm{C}$ $(712.2 \pm 124.4 \mathrm{U} / \mathrm{L})$ and chronic hepatitis $\mathrm{C}(232.3 \pm 15.8 \mathrm{U} / \mathrm{L} ; 0.001<\mathrm{p}<0.01)$ was significantly lower (Table 1 ). Besides, about $1 / 3$ of chronic hepatitis $C$ patients had normal serum ALT activity, but elevated serum CK-18 neoepitope concentration.

Normally, cytochrome C is not detectable in serum, but $47.45 \%$ of patients with chronic hepatitis $C$ had the increased level $(0.29 \pm 0.05 \mathrm{ng} / \mathrm{ml})$ of this apoptosis indicator (Table 1). Serum concentration of cytochrome $\mathrm{C}$ was even higher in acute hepatitides of viral and toxic etiologies.

\begin{tabular}{|c|c|c|}
\hline Patients & $\begin{array}{c}\text { Cytokeratin-18 U/L } \\
(\text { mean } \pm \text { SE) }\end{array}$ & $\begin{array}{c}\text { Cytochrome C ng/ml } \\
(\text { mean } \pm \text { SE) }\end{array}$ \\
\hline Acute hepatitis B & $1362.3 \pm 108.9(\mathrm{n}=11)$ & $1.52 \pm 1.14(\mathrm{n}=14)$ \\
\hline Acute hepatitis C & $712.2 \pm 124.4(\mathrm{n}=14)$ & $3.15 \pm 1.84(\mathrm{n}=3)$ \\
\hline Chronic hepatitis C & $232.3 \pm 15.8(\mathrm{n}=132)$ & $0.29 \pm 0.05(\mathrm{n}=129)$ \\
\hline Acute alcoholic hepatitis & $1003.9 \pm 104.3(\mathrm{n}=23)$ & $0.59 \pm 0.19(\mathrm{n}=58)$ \\
\hline
\end{tabular}

Reference intervals for: Cytokeratin-18 - 47.1-103.9 U/1, Cytochrome C -0

Table 1. Level of apoptosis markers in serum from patients with acute and chronic liver diseases. 
Very high serum concentration of HA was found in patients with acute alcoholic hepatitis $(1015.50 \pm 58.83 \mathrm{ng} / \mathrm{ml})$. Serum HA level was significantly higher in acute hepatitis B $(228.13 \pm 51.71 \mathrm{ng} / \mathrm{ml})$ than in acute hepatitis C $(58.33 \pm 27.22 \mathrm{ng} / \mathrm{ml}, \mathrm{p}<0.001)$. The level of serum HA in patients with chronic hepatitis was $103.82 \pm 15.47 \mathrm{ng} / \mathrm{ml}$ (Table 2).

\begin{tabular}{|c|c|c||}
\hline Patient group & Number of patients & $\begin{array}{c}\text { Hyaluronic acid } \\
\mathbf{n g} / \mathbf{m l} \\
\text { (mean } \pm \text { SE) }\end{array}$ \\
\hline Acute hepatitis B & 16 & $228.13 \pm 1.71$ \\
\hline Acute hepatitis C & 9 & $58.33 \pm 27.22$ \\
\hline Chronic hepatitis C & 132 & $103.82 \pm 15.47$ \\
\hline Acute alcoholic hepatitis & 22 & $1015.50 \pm 58.83$ \\
\hline
\end{tabular}

Reference interval: $0-75 \mathrm{ng} / \mathrm{ml}$

Table 2. Serum hyaluronic acid in patients with acute and chronic liver diseases.

In the present study we identified HLA-DRB1 alleles associated with the risk of HCV infection or protection in comparison with healthy subjects. Some differences in the strength of those markers are presented in Table 3.

HLA DRB1*07 (OR=7.0, p<0.0001), HLA-DRB1*03 (OR=1.95, $\mathrm{p}<0.035)$ and HLA-DRB1*05 $(\mathrm{OR}=1.66, \mathrm{p}<0.026)$ alleles were observed with the highest frequency, but DRB1*06, $(\mathrm{OR}=0.56, \mathrm{p}<0.034)$ and $\mathrm{DRB} 1 * 15$ alleles $(\mathrm{OR}=0.59, \mathrm{p}<0.020)$ - with the lowest frequency among patients with $\mathrm{HCV}$ infection.

Table 4 shows the association of different alleles of HLA class II genes with HCV infection and therapy. One hundred four patients received PEG-interferon + Ribavirin therapy. Fifty nine patients were characterized as responders, and the remaining 45 as non-responders.

\begin{tabular}{|c|c|c|c|c||}
\hline $\begin{array}{c}\text { Alleles } \\
\text { DRB1 }\end{array}$ & $\begin{array}{c}\text { HCV } \\
(\mathbf{n = 3 3 6 )}\end{array}$ & $\begin{array}{c}\text { Controls } \\
(\mathbf{n = 2 0 0 )}\end{array}$ & $\begin{array}{c}\text { Odds } \\
\text { Ratio }\end{array}$ & $(\boldsymbol{p})$ \\
\hline${ }^{*} 01$ & 48 & 31 & 0.91 & $<0.701^{* *}$ \\
\hline${ }^{*} 15$ & 49 & 45 & $\mathbf{0 . 5 9}$ & $<\mathbf{0 . 0 2 0}$ \\
\hline${ }^{*} 03$ & 43 & 14 & $\mathbf{1 . 9 5}$ & $<0.035$ \\
\hline${ }^{*} 04$ & 39 & 23 & 1.01 & $<0.970^{* *}$ \\
\hline${ }^{*} 05$ & 83 & 33 & $\mathbf{1 . 6 6}$ & $<0.026$ \\
\hline${ }^{*} 06$ & 29 & 28 & 0.56 & $<0.034$ \\
\hline${ }^{*} 07$ & 42 & 4 & $\mathbf{7 . 0}$ & $<0.000$ \\
\hline${ }^{*} 08$ & 3 & 14 & $\mathbf{0 . 1 2}$ & $<\mathbf{0 . 0 0 0}$ \\
\hline${ }^{*} 09$ & 0 & 2 & - & - \\
\hline${ }^{*} 10$ & 0 & 5 & - & - \\
\hline \hline
\end{tabular}

${ }^{* *}$ Cornfield not accurate. Extract limits preferred.

Bold-face type highlihts statistically significant associations for patient's vs controls.

p-probability (l-p) * $100 \%$, OR - odds ratio

$\mathrm{n}=$ number of haplotypes (eg, 336 alleles from 168 individuals). Nature of valve lesions was not reported on 2 patients.

Table 3. The frequency of identified DRB1* alleles in HCV patients and control subjects. 


\begin{tabular}{|c|c|c|c|c|c|c|c|}
\hline DRB1* alleles & ${ }^{*} 01$ & ${ }^{* 15}$ & ${ }^{*} 03$ & ${ }^{*} 04$ & ${ }^{*} 05$ & ${ }^{*} 06$ & ${ }^{*} 07$ \\
\hline $\begin{array}{c}\text { Patients in total } \\
n=168 \\
\text { (general group) }\end{array}$ & 0.18 & $\begin{array}{c}0.59 / \\
(0.020)\end{array}$ & $\begin{array}{c}1.95 / \\
(0.035)\end{array}$ & & $\begin{array}{l}1.66 / \\
(0.026\end{array}$ & $\begin{array}{c}0.56 / \\
(0.034)\end{array}$ & $\begin{array}{c}7.0 / \\
(0.000)\end{array}$ \\
\hline $\begin{array}{c}\text { Effective PEG } \\
\text { INF+Ribavirin } \\
\text { therapy } \\
\text { (group A) n=59 }\end{array}$ & 0.14 & 0.14 & 0.13 & $\begin{array}{l}1.79 / \\
0.014\end{array}$ & 0.21 & $\begin{array}{c}4.29 / \\
(0.003)\end{array}$ & 0.03 \\
\hline $\begin{array}{c}\text { Noneffective PEG } \\
\text { INF+Ribavirin } \\
\text { therapy } \\
\text { (group B) } n=45\end{array}$ & 0.16 & 0.16 & 0.12 & 0.08 & $0.62 / 0.013$ & 0.06 & $\begin{array}{l}0.18 / \\
0.005\end{array}$ \\
\hline $\begin{array}{c}\text { Effective Realdiron } \\
\text { therapy (group C) } \\
n=30\end{array}$ & $\begin{array}{l}2.58 / \\
0.071\end{array}$ & 0.13 & 0.13 & 0.08 & 0.22 & 0.07 & 0.13 \\
\hline $\begin{array}{c}\text { Noneffective } \\
\text { Realdiron therapy } \\
\text { (group D) } n=34\end{array}$ & 0.09 & 0.16 & 0.13 & $\begin{array}{l}0.53 / \\
0.065\end{array}$ & 0.77 & 0.74 & 1.15 \\
\hline $\begin{array}{l}\text { Control subjects } \\
\text { (group E) n=100 }\end{array}$ & 0.16 & 0.23 & 0.07 & 0.12 & 0.17 & 0.15 & 0.02 \\
\hline
\end{tabular}

Bold-face type highlights statistically significant associations for patient's vs controls. gf (gene frequency), p (probability), OR (odds ratio) and value are reported only for significant associations ( $\mathrm{p}<0.05)$. $\mathrm{n}=$ number of haplotypes (eg, 336 alleles from 168 individuals).

Table 4. Association of different alleles of HLA class II genes with HCV infection and therapy.

Sixty four patients received Realdiron therapy. Thirty patients were characterized as responders, and the remaining 34 as non-responders. All individuals in the study were genotyped for HLA class II DRB1*alleles.

HLA-DRB1*06(OR=4.29, $\quad \mathrm{p}<0.003)$ and $\quad$ HLA-DRB1*04 $\quad(\mathrm{OR}=1.79, \quad \mathrm{p}<0.014) \quad$ Major Histocompatibility class II alleles were significantly associated with the effective response to PEG interferon + Ribavirin therapy in patients. Our results therefore provide evidence that the presence of HLA-DRB1*06 and HLA-DRB1*04 is an important additional factor for predicting a long-term response to PEG-interferon + Ribavirin therapy in patients with chronic hepatitis $\mathrm{C}$.

The results of class II HLA distribution in patients with HCV are presented in Table 4.

HLA-DRB1*01 was detected among patients of group $C$ and D and it was significantly associated $(\mathrm{OR}=2.58, \mathrm{p}<0.071)$ with the effective response to Realdiron therapy in chronic hepatitis $C$ patients. HLA-DRB1*04 $(\mathrm{OR}=0.53, \mathrm{p}<0.065)$ was found as an indicator of nonresponders to Realdiron therapy in group $\mathrm{D}$. In both groups - C and D, the frequency of the remaining HLA antigens was of minor importance.

Liver biopsy is not always possible or reproducible, it cannot be performed frequently and is a costly invasive procedure with a certain, although low, risk of serious complications. Histological examination of the liver does not provide information about the dynamics of hepatic fibrogenesis, liver biopsy provides only static information about fibrotic process. Non-invasive markers that reflect fibroproliferative activity in the liver and the treatment response would be preferable. Serum hyaluronic acid has been identified as a potential marker of fibrosis evolution.

The clinical benefit of the existing markers may be limited by the etiology or stage of disease. Hyaluronate can be used as a specific marker to detect liver fibrosis (Afdhal\&Nunes, 2004) and 
has been found to correlate with severity of the disease (Lackner C. et al., 2005). Findings of Kawamoto et al. (2006) suggest that hyaluronate can be used to assess severe liver fibrosis or cirrhosis, but it would be difficult to assess liver fibrosis at its early stage.

According to Suzuki et al. (2005), hyaluronic acid has been reported to have a high diagnostic performance in assessing the severity of hepatic fibrosis in patients with alcoholic liver disease.

In the context of above mentioned our findings don't contradict with conclusions of those investigators, particularly, in case of acute alcoholic hepatitis, when level of hyaluronic acid in blood serum is very high (see Table 2).

Performed parallel histological investigations of liver biopsies from patients with chronic hepatitis C illustrated the heterogeneity of hepatic fibrosis degree. Serum HA levels didn't significantly correlate with the degree of hepatic fibrosis found in these patients. HA could be a marker of hepatic fibrosis progression. In chronic liver diseases, serial HA levels have been advocated as the means to monitor disease progression and to limit the need for follow-up liver biopsy.

The results of performed investigation on main apoptosis markers (cytokeratin-18 neoepitope, cytochrome C) demonstrated very significant involvement of apoptosis (including mitochondrial way) in pathogenesis of acute hepatitis, independently of etiology. This presumption was confirmed by high level of apoptosis markers in serum (see Table 1). The delineation of the signalling patways that mediate apoptosis has changed the paradigms of understanding of many liver diseases (Schattenberg et al., 2006). Apoptosis is the normal physiological response to many chemical, physical and biological stimuli. Mitochondria and cell surface receptors mediate the two main pathways of apoptosis (Reed, 2000). Hypoxia has been shown to promote apoptosis (Holmgren L. et al., 1995). As apoptosis is closely involved in the process of liver disease progression, the treatment of ischemic injury remains one of the most challenging areas of hepatology today.

Apoptosis defines a type of cell death distinct from the more conventional necrotic death on the basis of characteristic morphological features. Although these descriptions and distinctions are useful, there is a great deal of overlap between apoptosis and necrosis in morphological features and biochemical events. Indeed, apoptosis is frequently followed by secondary necrosis of cells, especially, if there is failure of clearance or ingestion of apoptotic bodies (Bennett, 2002).

One of the aims of our study was to confirm the influence of HLA class II genes on the progression of $\mathrm{HCV}$ infection and to assess a possible relationship between these genes and different therapies. For this purpose we used the PCR-SSP test which permits the routine determination of the distribution of HLA class II genes. We confirmed that the frequency of HLA-DRB1*06 (4.29/0.003)and ${ }^{*} 04(1.79,0.014)$ was significantly higher in patients from group A than in patients from group B. In general group HLA-DRB1*07 and HLA-DRB1*05 alleles were observed.HLA-DRB1*07 was found as an indicator of nonresponders to PEG-interferon + Ribavirin therapy (group B).

In all HCV patient groups, a correlation was found between certain HLA genes and the extent of liver damage. Among the host-related factors which have an important role in determining the outcome of HCV infection, certain HLA class II genes appear crucial for resolution or progression of hepatitis $\mathrm{C}$.

Accumulation evidence regarding the limitations of biopsy have led some to suggest that non-invasive markers should replace biopsy as the initial method for disease staging. But 
further research is needed to evaluate the long-term effectiveness of the these strategies before a global recommendation can be made (Mehta et al., 2009). It is widely appreciated that substantial error has been observed when biopsy specimens have been compared to the full liver (Colloredo et al., 2003).

There are several advantages in using non-invasive markers: they can be used to accurately define an appropriate time for treatment initiation, they can help monitoring and assess the therapeutic efficacy of antiviral treatment in case of liver fibrosis and cirrhosis, etc., they are crucial to evaluate the performance of non-invasive markers used for diagnosis of liver fibrosis and apoptosis in HAV, HBV, HCV, HIV-infected patients.

A number of radiological methods are used in diagnosis of various chronic liver diseases. The first of them most often is ultrasonography (US). Signs of liver cirrhosis in B-mode image are well known. They are the irregularity and nodularity of liver surface, coarse nodularity of parenchyma structure, lobus caudatus hypertrophy, as well as symptoms of portal hypertension such as splenomegaly, ascites and portocaval shunts. The specificity of the method in detection of cirrhosis is in the range from $80 \%$ to $100 \%$, sensitivity - from $43 \%$ to $88 \%$ (Needleman et al, 1986; Giorgio et al., 1986; Di Lelio et al., 1989; Gaiani et al., 1997; Colli et al., 2003; Vigano M. et al., 2005). Irregularity and nodularity of the liver surface caused by altering foci of regeneration nodules and necrosis (Poff et al., 2008) can be better assessed using high-frequency linear probe (Colli et al., 2003.; Nishiura et al., 2005). Nodularity of the structure is a prognostic sign of increased risk of developing hepatocellular carcinoma. This symptom is more common in liver cirrhosis of HDV hepatitis origin $(51 \%)$, less common in other causes of diseases (9\%) (Caturelli et al., 2003). A significant sign of liver cirrhosis is splenomegaly. The spleen size which overexceeds $15 \mathrm{~cm}$ is a symptom with $98 \%$ specificity and $57 \%$ sensitivity ( $\mathrm{O}^{\prime}$ Donohue et al., 2004). By combining sonographic symptoms of B-mode imaging in a common system several researchers have gained increment of specificity of the method (Nishiura et al., 2005). Liver cirrhosis is characterized by changes in liver size and its proportion: atrophy of the right lobe and the medial segment of the left lobe as well as hypertrophy of lobus caudatus and the lateral segment of the left lobe (Giorgio et al., 1986; Lafortune et al., 1998). In total, the diagnostic accuracy of US in detection of liver cirrhosis is high enough, while its applicability in precirrhotic stages of the disease is limited.

As chronic liver disease progresses, numerous processes occur in the structure altering liver blood flow. Under normal conditions liver receives $70-75 \%$ of blood through the portal vein, $25-30 \%$ through the hepatic artery, leaving a very small fraction for such tiny blood vessels as aberrant gastric veins, particularly the right (Matsui et al., 1995) which occurs in about 6-14 \% of patients, a.phrenica $d x$, parabiliary veins (Couinaud, 1988), gallblader vein, which sometimes is drained directly to the liver. As a result of cirrhotic and fibrotic processes presinusoidal and sinusoidal occlusion develops there which increases resistance for the blood flow through the liver. A portal hypertension develops, if the pressure gradient overexceeds $10 \mathrm{~mm} \mathrm{H}_{2} \mathrm{O}$ (Zwiebel\&Pellerito, 2005). Due to the increased resistance as the portal blood flow diminishes, there is a compensatory increment of the flow in the hepatic artery (Burton-Opitz, 1911; Kock et al., 1972). As a result of the increment of the pressure in the portal vein, its size and pulsations are altered, blood flow slows down and later changes its direction from hepatopetal to hepatofugal. Increase in pressure in the portal vein is compensated through portocaval anastomoses. The hepatic artery itself does not have such a mechanism. It is compensated through very tiny (under normal conditions) anastomoses between portal and arterial 
system, which are located in the liver sinusoides, vasa vasorum of the portal vein and peribiliary vascular plexes. If transhepatic resistance overexceeds resistance of portosystemic collaterals, a shunting of arterial flow to the portal system starts to occur (Sacerdoti et al., 1995; Piscaglia et al., 1997). Flow characteristics and their changes in liver blood vessels are well detectable in doplerographic examinations. Veins of portal systems - v.portae, v.mesenterica sup., v.lienalis, as well as hepatic artery and liver veins are well visible in approximately $93-95 \%$ of patients undergoing liver sonography (Zwiebel \& Pellerito, 2005).

A number of parameters and indexes are offered to assess and detect portal hypertension. They are: diameter of the portal vein, change of the size of v.portae and v.lienalis during the respiratory cycle, flow rate and direction in the portal vein, pulsitility of Doppler spectral waveform as well as congestation index, respectively: ratio between cross-sectional area of the portal vein and the flow velocity within it, the resistance index in the hepatic artery, portal and hepatic artery velocity rate, etc. Many studies have been performed regarding utility of all these parameters in diagnostics of liver cirrhosis, however the results are still controversial.

One of the signs of liver cirrhosis and portal hypertension is hepatofugal flow in the portal vein, i.e., the flow away from the liver. This sign is found in $3-23 \%$ of cirrhosis patients (Kawasaki et al., 1989; Gaiani et al., 1991; Taourel et al., 1998; von Herbay et al., 2001). Incidence of this symptom depends on the severity of the disease. The flow direction in the portal vein is influenced also by development of the paraumbilical shunts, retaining the hepatopetal flow in cirrhosis patients. Hepatofugal flow can also be found in patients with extrahepatic shunts (splenorenal, oesophageal, retroperitoneal, etc.).

The portal flow velocity, which is an easily assessable measure, is a variable parameter. In healthy subjects in various studies it ranges from $13.7 \mathrm{~cm} / \mathrm{s}$ to $22 \mathrm{~cm} / \mathrm{s}$ (O'Donohue et al., 2004; Walsh et al., 1998; Bernatik et al., 2002). With the development of liver cirrhosis it declines. For the diagnosis of liver cirrhosis using a cut-off value of 13 to $15 \mathrm{~cm} / \mathrm{s}$ the sensitivity is $74.5 \%$ to $88 \%$, the specificity - 53\% to $96 \%$ (Zironi et al., 1992; Schneider et al., 2005; Iwao et al., 1997). In precirrhotic stages there is no significant difference in velocity of the portal flow from healthy subjects (Bernatik et al., 2002; Schneider et al., 2005).

Under normal conditions the flow in the portal vein is continuous and hepatopetal but its velocity is slightly pulsatile during the heart cycle. These pulsations cause a pressure change in the right atrial flow initiated by fluctuations in the lower vena cava which through the liver veins and sinusoides are transmitted to v.portae. Pronounced pulsations in the portal vein in patients with right heart diseases serve as the evidence of such explanation of the pulsation mechanism (Görg et al., 2002). Besides, there is also influence of the adjacent hepatic artery pulsations and respiratory cycle phases. Presinusoidal obstruction, collagenisation of the Disse space and enlargement of hepatocytes due to liver fibrosis and cirrhosis may prevent the transmission of pulsations from the heart and liver veins. Flatened Doppler waveform of the portal vein could therefore be a sign of liver fibrosis and cirrhosis. Undulating Doppler waveform of the portal vein in healthy subjects is found in $63.8 \%-100 \%$ of cases. The degree of pulsatility of the portal vein quantitatively is characterized by two indexes: the ratio between minimal and maximal flow velocity as well as pulsation index (PI) in which the maximal flow rate is extended to the difference between the minimum and the maximum flow rate. The minimum and maximum velocity ratio $>0.54$ for healthy subjects is higher than $90 \%$ of cases (Gallix et 
al., 1997). In liver cirrhosis patients reduced hepatic vein pulsatility is found significantly more often than in patients with lower degrees of fibrosis or in healthy subjects, however, the incidence in different studies varies considerably. Distinguishing between various degrees of severity of fibrosis in this manner fails (Schneider et al., 2005; Barkat, 2004; Maktanir et al., 2005).

In a number of studies the measurement of size of the portal vein is used as one of the methods of detecting portal hypertension. In most cases in healthy subjects the portal vein is smaller than in patients suffering from cirrhosis and various degrees of liver fibrosis, although these differences are not statistically significant and a large overlap of values is found (O'Donohue et al., 2004; Lim et al., 2005; Kutlu et al., 2002). Similar results were gained when determining the liver congestation index, calculated by extending v.portae diameter to the average blood flow velocity in it (Walsh et al., 1998; Lim et al., 2005), although some studies provide evidence of the ability of this feature to differentiate liver cirrhosis from other conditions (Kutlu et al., 2002).

As the sinusoidal resistance increases and the portal flow decreases there is a compensatory increment of the flow in the liver artery. Since the increase of resistance also affects the arterial system, changes occur in haemodynamic parameters recordable in Doppler waveform as well as increase of the resistance index and growth of the volume. Under normal conditions a Doppler waveform of hepatic artery of healthy subjects is of low pulsitility with antegrade flow within whole diastole. Resistance index (RI), determined by extending the peak systolic and end-diastolic velocity difference to the peak systolic velocity in healthy subjects ranges from 0.5 to 0.7 (Vilgranin, 2001). In cirrhotic patients RI within different studies ranges from 0.68 to 0.98 , in precirrhotic stages of the disease - from 0.58 to 0.73 ( $\mathrm{O}^{\prime}$ Donohue et al., 2004; Bernatik et al., 2002; Haktanir et al., 2005; Lim et al., 2005; Pierce\&Sewell, 1990). The overlap of these parameters significantly limits the use of dopplerographic parameters of hepatic arteries in diagnostics. No studies have yielded results that would reliably differentiate various degrees of fibrosis from each other.

In some trials a number of other arterial flow factors have been used, as the mean flow velocity $(\mathrm{cm} / \mathrm{s})$, minute volume flow $(\mathrm{ml} / \mathrm{min})$, liver perfusion index (hepatic artery and common liver flow ratio), however, they have not gained wide acceptance.

One of the most widely used liver vascular ultrasound examination is hepatic vein dopplerography. In most cases liver veins are easily visible tubular structure, with diameter changing during the respiratory cycle. In healthy subjects $2 \mathrm{~cm}$ away from the inflow to $v$. cava inferior it is $4-6 \mathrm{~mm}$ but less than $1 \mathrm{~cm}$ (Bolondi et al., 1991). In cases of various diseases, such as the right heart diseases, circulatory congestion in the large vasculatory circle, severe liver steatosis, Budd-Chiary syndrome, etc. vein size may vary. Blood flow in liver veins is markedly pulsating, changing directions with different phases of the cardiac cycle. During the diastole of the heart atria and ventriculi it is antegrade, respectively towards the heart, or away from the liver. During the atrial systole the flow is retrograde or towards the liver. Healthy liver is elastic and easily responds to the pressure changes in liver veins during heart cycle phases. In the Doppler waveform of liver veins these fluctuations are reflected as two antegrade waves followed by a single retrograde wave. Haemodynamics of the liver veins is detailed in the L.Bolondi study in 1991. (Fig.1) 


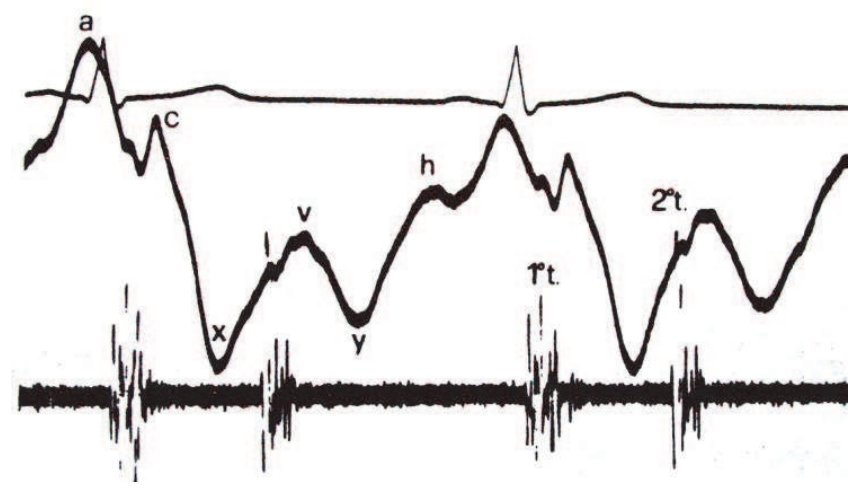

Fig. 1. Mechanism of wave formation in VHDx Doppler waveform. Simultaneous record of ECG, phonocardiogram and Doppler waveform of the jugular vein (adapted from Bolondi L et al, Radiology 1991; 178:513-516.)

Wave A (+) - atrial systole. Retrograde flow in VCI and VH. Wave C (+) - a small positive wave in the descendent part or the A wave which is caused by closing of tricuspidal valves. Wave X (-) - ventricular systole and atrial relaxation (diastole). Antegrade flow during filling of the atrium. Wave $\mathrm{V}(+)$ - atrial filing. The peak of the wave shows opening of tricuspidal valves at the beginnning of ventricular diastole. Wave Y (-) - ventricular diastole. Atrial emptying towards ventriculi.

In order to assess the Doppler waveform of hepatic veins a number of methods are recommended. The most widespread method was introduced by Bolondi. He advised to divide all curves into 3 groups: triphasic, showing a positive wave due to retrograde flow during the atrial systole, biphasic, with no positive wave, but with saved pulsations, and fully flattened or monophasic appearance. This method is simple, easy to use and reproducible.

Flow type of hepatic veins, respectively, shape of Doppler waveform of liver veins, is dependent on a number of diseases and conditions. Incidence of flattened curve significantly increases during pregnancy and increases as pregnancy progresses (Roobottom et al., 1995). In case of regurgitation and insuficience of tricuspidal valves during ventricular systole the blood is pushed backwards to atria and - further - to v.cava inferior and to hepatic veins. In their Doppler waveform the systolic wave $X$ reduces, disappears and becomes retrograde and interacts with wave A (Abu-Yousef, 1991). Also, in case of constrictive pericarditis changes in hepatic vein Doppler waveform are seen (von Birbra et al., 1989).

Pathological processes within liver veins themselves, as Budd-Chiari syndrome and venoocclusive disease or sinusoidal obstruction syndrome, are seen and diagnosed by B-mode and Doppler ultrasound methods. Unlike Budd-Chiari syndrome, in cases of veno-occlusive disease main liver veins can be patent (Desser et al., 2003).

Flow in liver veins is influenced by intra-abdominal and intrathoracic pressure. In patients with triphasic waveform during deep inspiration and Valsalva test the waveform often paves and becomes monophasic or biphasic (Techgraber et al., 1997). Due to this reason liver vein examination is held during mild, superficial inspiration or mild expiration following mild inspiration. 
One of the basic factors influencing the type of liver flow is the physical condition of the liver, its hardness and elasticity. With increase in hardness and decrease in elasticity liver tissue looses compliance with hepatic venous pulsations caused by variations in pressure within them. Haemodynamically it is expressed as loss of changing of flow direction during atrial systole in v.cava inferior and hepatic veins what can be registered by Doppler ultrasound. The feasibility that the hepatic veins Doppler waveform assesses changes in liver structure, resp., fibrosis and cirrhosis, has been investigated by many researchers, and the results are generally better than in other hepatic circulatory dopplerographic measurements, although not very clear.

Flattened, resp., biphasic or monophasic hepatic vein Doppler waveforms in liver cirrhosis patients with varying forms of cirrhosis, occur in 50\% (Bolondi et al., 1991) to 85\% (Barkat, 2004) cases. With increasing severity of cirrhosis, the frequency of flattened curves increases (von Herbay et al., 2001; Barkat, 2004). The sensitivity and specificity of the method to detect cirrhosis are $37 \%-75 \%$ and respectively $41 \%-100 \%$, respectively (Colli et al., 2003; Schneider et al., 2005; Arada et al., 1997). In precirrhotic stages of the disease with increase of fibrosis stage the incidence of flattened waveform tends to increase. In some studies this increase is statistically significant (O'Donohue et al., 2004; Schneider et al., 2005), while in others it is insignificant, there is overlap between the results (Bernatik et al., 2002; Lim et al., 2005). This leads to critical assessment of hepatic vein Doppler ultrasound ability to detect the precirrhotic forms or differentiate between degrees of fibrosis, while the diagnosis of cirrhosis flattened Doppler waveform is a key symptom. (Fig.2,3)

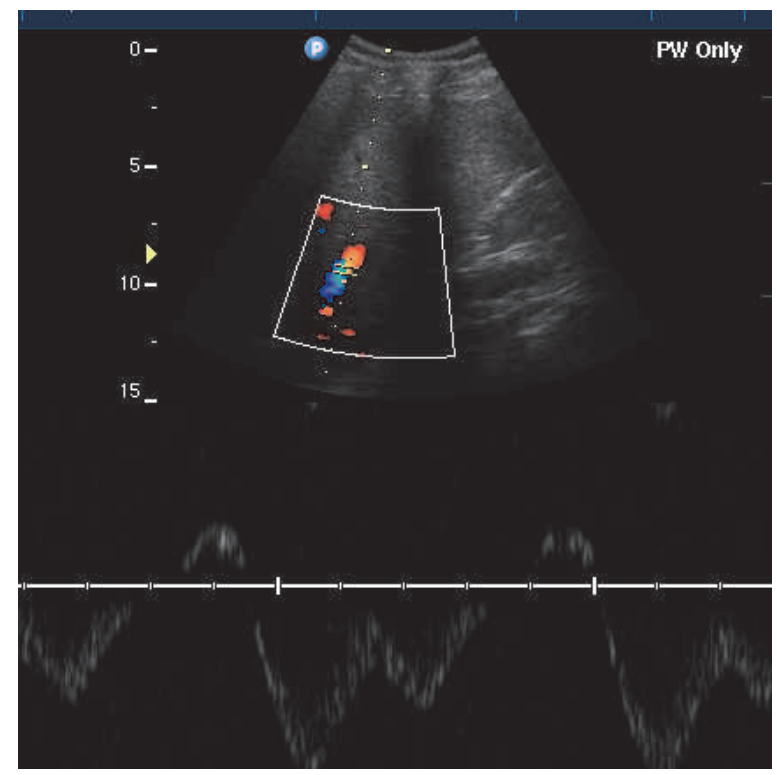

Fig. 2. Triphasic VHDx Doppler waveform in 29 y.o. patient with mild (Knodell F1) liver fibrosis and without liver steatosis (S-0).

Liver steatosis also should be taken into account when assessing liver veins Doppler ultrasound results. The increased fat in the liver increases the pressure on the hepatic veins and reduces liver tissue compliance to venous pulsations. In patients with severe liver steatosis 
(> 66\% of hepatocytes affected by fat) flattened hepatic vein Doppler waveform is found significantly more frequently than in patients without steatosis or those with mild forms in respectively $90 \%$ vs. $5 \%-20 \%$ of cases (Schneider et al., 2005). Sensitivity of the method in detecting severe steatosis is $88 \%$, specificity $74 \%$ (Schneider et al., 2005). It should be noted that appearance of liver steatosis in B-Mode ultrasound image has been researched much, however, its effect on blood flow types in hepatic veins, the dependence on the morphological forms of steatosis (macrovesicular or microvesicular) has been assessed much less frequently. (Fig.4)

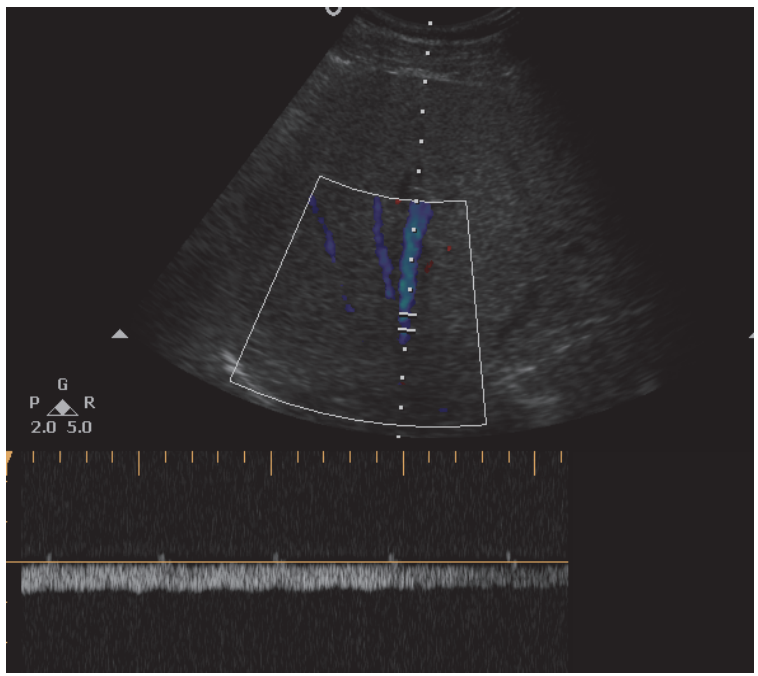

Fig. 3. Monophasic VHDx Dopler waveform in 53 y.o. patient with moderate severity of liver fibrosis (Knodell F-3) and severe mixed type (macro - microvesiculare) steatosis (S3). There are no typical steatosis signs in B- mode image

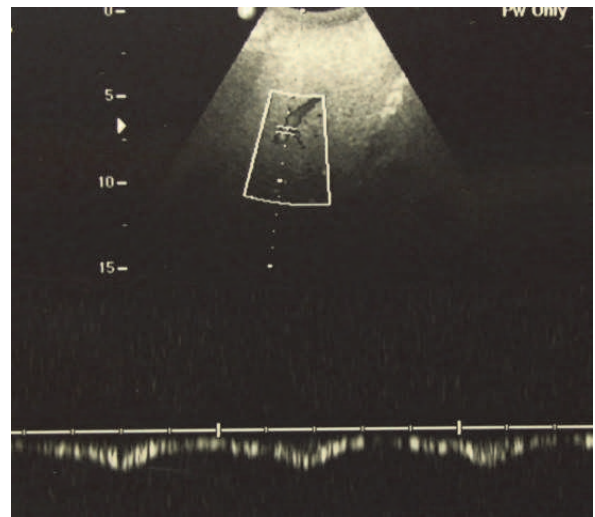

Fig. 4. Biphasic VDHx waveform in 44 y.o. patient with moderate liver steatosis (S-2) and mild fibrosis (F-1). In B-Mode image appearance of expressed steatosis is visible: increased liver exhogenicity, impaired visualization of deeper tissues and diaphragmal line. 


\section{Conclusion}

Evaluation of apoptosis by estimating CK-18 neoepitope level should be included into hepatitis virus infection and toxic liver damage management algorithm. Apoptosis, not only necrosis, is essentially involved in liver damage development mechanisms in acute and chronic HBV and HCV infection. Monitoring of serum apoptotic CK-18 neoepitope level might be useful for the appropriate estimation of liver diseases therapy efficacy and open new approach to apoptosis therapeutic regulation.

If in alcoholic hepatitis apoptosis may be a principal cause of cell death, then in acute hepatitis B cell death would be associated with both cell apoptosis and cell necrosis.

As fibrotic process is dynamic, serum hyaluronic acid levels may show fibrogenesis rather than developed and formed fibrosis. Circulating HA measurement has been proposed for operative monitoring of fibrotic lesion dynamics in acute and chronic liver damages.

The punctual identification of immunogenetic factors may prove to be useful in predicting disease evolution, in guiding the appropriate therapy for patients with poor prognosis, and in encouraging the development of untherapeutic strategies.

As regards to the potential of US to assess the diagnosis of diffuse liver disease, it must be concluded that the method is applied to the detection of manifest cirrhosis. In detection of precirrhotic stages and differentiation between them the options are greatly restricted and the liver biopsy cannot be replaced. Liver vein Dopplerography can be applied in liver screening examinations to detect occult liver diseases. It can be also applied in follow-up of diffuse liver diseases, however, this suggestion still requires further studies.

\section{Acknowledgement}

This study was financially supported by the Project No 9.1. of National Program No 4.

\section{References}

Abu-Yousef, M.M. (1991). Duplex Doppler Sonography of the Hepatic vein in Tricuspid Regurgitation. AJR, Vol.156, pp.79-83

Afdhal, N.H. \& Nunes, D. (2004). Evaluation of liver fibrosis: a concise rerview. Am. J. Gastroenterol., Vol.99, pp.1160-1174

Arada, K., Ofelli, M., Calikoglu, U. et al. (1997). Hepatic vein Doppler waveform changes in early stage (Child-Pugh A) chronic liver parenchimal diseases. J.Clin.Ultrasound, Vol.25, pp.15-19

Barkat, M. (2004). Non-pulsatile hepatic and portal vein waveforms in patients with liver cirrhosis: concordant and disconcordant relationships. British J Radiology, Vol.77, pp.547-550

Bedossa, P.\&Poynard, T. (1996). An algorithm for the grading of activity in chronic hepatitis C. The METAVIR Cooperative Study Group. Hepatology, Vol.24, No.2, pp.289-293

Bedossa, P.\&Carrat, F. (2009). Liver biopsy: the best, not the gold standard. J. Hepatology, Vol.50, No.1, pp.1-3

Bedossa, P. (2009). Assessment of hepatitis C: non-invasive fibrosis markers and/or liver biopsy. Liver international, Vol.29, S.1, pp.19-22

Bennett, M.R. (2002). Apoptosis in the cardiovascular system. - Heart, Vol.87, No.5, pp.480487 
Bernatik, T., Strobel, D., Hahn, E.G.\&Becker, D. (2002). Doppler measurements: a surrogate marker of liver fibrosis? European Journal of Gastroenterology and Hepatology, Vol.14, pp.383-387

Bialecki, E.S.\&Bisceglie, A.M. (2005). Diagnosis of hepatocellular carcinoma. HPB, Vol.7, pp. $26-34$

Bolondi, L., Bassi, S.L. et al. (1991). Liver cirrhosis: changes of Doppler waveform of hepatic veins. Radiology, Vol.178, pp.513-516

Bottero, J., Lacombe, K., Guéchot, J., Serfaty, L., Miailhes, P., Bonnard, P., Wendum, D., Molina, J.-M., Lascoux-Combe, C. \& Girard, P.-M. (2009). Performance of 11 biomarkers for liver fibrosis assessment in $\mathrm{HIV} / \mathrm{HBV}$ co-infected patients. J. Hepatology, Vol.50, No.6, pp.1074-1083

Bravo, A.A., Sheth, S.G.\&Chopra S. (2001). Liver biopsy. N Engl J Med, Vol.344, No.7, pp.495 $-500$

Brown, K.E., Janney, C.G.\&Brunt, E.M. (2000). Liver biopsy: indications, technique, complications, and interpretation. In: Liver disease: diagnosis and management. Bacon, B.R.; DiBisceglie, A.M. (Eds.) 47-75, Churchill Livingstone, New York

Burton-Opitz R. (1911). The vascularity of the liver: the influence the portal blood flow upon the flow in the hepatic artery. Experimental Physioloy, Vol.4, pp.93-102

Carpenter, H.A.\&Czaja, A.J. (2002). The role of histoogic evaluation in the diagnosis and management of autoimmune hepatitis and its variants. Clin Liver Dis, Vol.6, No.3, pp.685 - 705

Caturelli, E., Castellano, L., Fussili, S. et al. (2003). Coarse nodular pattern in hepatic cirrhosis: risk for hepatocelular carcinoma. Radioloogy, Vol.226, pp.691-697

Churukian, C.L. Pigments and minerals. (2002). In: Theory and practice of histological techniques, 5th ed. Ed by Bancroft, J.D. and Gamble, M. (Ed.) 243-268, Churchill Livingstone, Edinburgh (International edition)

Clark, P., Britton, L.J., Powell, L.W. (2010). The diagnosis and management of hereditary haemochromatosis. Clin Biochem Rev, Vol.31, pp.3 - 8

Colli, A., Fraquelli, M., Andreoletti, M. et al. (2003). Severe Liver Fibrosis or Cirrhosis: Accuracy of US for Detection - Analysis of 300 Cases. Radiology, Vol.227, pp.89-94

Colli, A.\&Fraquelli, M. (2009). What is the actual role of diagnosis and how to assess it? J of hepatology, Vol.50, No.4, pp.827-829

Colloredo, G., Guido, M., Sonzogni, A. \& Leandro, G. (2003). Impact of liver biopsy size on histological evaluation of chronic viral hepatitis: the smaller the sample, the milder the disease. J. Hepatology, Vol.39, pp.239-244

Couinaud C. Parabiliary venous sistem. (1988). Surg Radiol Anat, Vol.10, pp.311-316

Czaja, A.J.\&Carpenter, H.A. (2003). Histologic features associated with relapse after corticosteroid withdrawal in type 1 autoimmune hepatitis. Liver Int, Vol.23, No.2, pp.116 - 123

Desmet, V.J.\&Rosai, J. (2004). Liver. In: Rosai and Ackerman's surgical pathology, 9th ed. Rosai J. Mosby (ed.), 917-1034, Edinburgh (International Edition)

Desser, T.S., Sze, D.Y.\&Brook, J.R. (2003). Imaging and intervention in the hepatic veins. AJR, Vol.180, pp.1583-1591

Di Lelio A., Cestari, C., Lomazzi, A., Beretta, L. (1989). Cirrhosis: diagnosis with sonographic study of the liver surface. Radiology, Vol.172, pp.389-392 
Dioguardi, N., Grizzi, F., Fiamengo, B.\&Russo, C. (2008). Metrically measuring liver biopsy: A chronic hepatitis B and C computer-aided morphologic description. World J Gastroenterol, Vol.14, No.48, pp.7335 - 7344

Feld, J.J. (2005). Autoimmune hepatitis: effect of symptoms and cirrhosis on natural history and outcome. Hepatology, Vol.42, No.1, pp.53 - 62

Gaiani, S., Bolondi, L., Bassi, L. et al. (1991). Prevalence of spontaneous hepatofugal flow in liver cirrhosis: clinical and endoscopic correlation in 228 patients. Gastroenterology, Vol.100, pp.160-167

Gaiani, S., Grammantieri, L., Venturoli, N. et al. (1997). What is the criterion differentiating chronic hepatitis from compensated cirrhosis: a prospective study comparing ultrasonography and percutaneous liver biopsy. J of Hepatology, Vol.27, pp.979-985

Gallix, B.P., Taovrel, P., Dauzat, M. et al. (1997). Flow pulsatility in the portal venous system: a study of Doppler sonography in the healthy adults. AJR, Vol.169, pp.141144

Gamble, M.\&Wilson, I. (2002). The hematoxylins and eosin. In: Theory and practice of histological techniques, 5th ed. Bancroft, J.D. and Gamble, M. (Ed.), 125-138, Churchill Livingstone, Edinburgh (International edition)

Giorgio, A., Amoroso, P., Lettieri, G. et al. (1986). Chirrosis: value of caudate to right lobe ratio in diagnosis with US. Radiology, Vol.161, pp.443-445

Görg, C., Riera-Knorrenschild, J.\&Diterich, J. (2002). Colour Doppler ultrasound patterns in the portal venous system. British J of Radiology. Vol.75, pp.919-929

Haktanir, A., Songul, B., Celenk, C. et al. (2005). Value of Doppler sonography in assessing the progression of chronic viral hepatitis and in the diagnosis and grading of cirrhosis. J Ultrasound Med., Vol.24, pp.311-321

Hamato, N., Moriyasu, F., Someda, H., Nishikawa, K., Chiba, T. et al. (1997). Clinical aplication of hepatic venous hemodinamics by Doppler ultrasonography in chronic liver disease. Ultrasound Med Biol, Vol.23, pp.829-835

Hayashi, P.H., Trotter, J.F., Forman, L., Kugelmas, M., Steinberg, T., Russ, P. et al. (2004). Impact of pretransplant diagnosis of hepatocellular carcinoma on cadaveric liver allocation in the era of MELD. Liver Transpl, Vol.10, pp.42 - 48

Hohenester, S., Oude-Elferink, R.P.J.\&Beuers, U. (2009). Primary biliary cirrhosis. Semin Immunopathol, Vol.31, pp.283 - 307

Holmgren, L., O’Reilly, M.S. \& Folkman, J. (1995). Dormancy of micrometastases: balanced proliferation and apoptosis in the presence of angiogenesis suppression. Nat. Med., Vol.1, pp.149-153

Hultcrantz, R.\&Gabrielsson, N. (1993). Patients with persistent elevation of aminotransferases: investigation with ultrasonography, radionuclide imaging and liver biopsy. J Intern Med, Vol.233, pp.7 - 12

Ishak, K., Baptista, A., Bianchi, L., Callea, F., De Groote, J., Gudat, F., Denk, H., Desmet, V., Korb, G., MacSween, R.N. et al. (1995). Histological grading and staging of chronic hepatitis. J Hepatol, Vol.22, No.6, pp.696 - 699

Iwao, T., Toyonaga, A., Oho, K. et al. (1997). Value of portal Doppler ultrasound parameters of portal vein and hepatic artery in diagnosis of cirrhosis and poral hypertnesion. Am J Gastroenterology, Vol.92, pp.1012-1017 
Jones, M.L. (2002). Connective tissues and stains. In: Theory and practice of histological techniques, 5th ed. Bancroft, J.D.\&Gamble, M. (Eds.), 139-162, Churchill Livingstone, Edinburgh (International edition)

Kawamoto, M., Mizuquchi, T., Katsuramaki, T., Nagayama, M., Oshima, H., Kawasaki, H., Nobuoka, T., Kimura, Y. \& Hirata, K. (2006). Assessment of liver fibrosis by non invasive method of transient elastography and biochemical markers. World J. Gastroenterol., Vol.12, No.27, pp.4325-4330

Kawasaki, T., Moryasu, F., Nishida, O. et al. (1989). Analysis of hepatofugal flow in portal venous system using ultrasonic Doppler duplex system. Am J Gastroenterology, Vol.148, pp.47-49

Knodell, R.G., Ishak, K.G., Black, W.C., Chen, T.S., Craig, R., Kaplowitz, N., Kiernan, T.W., Wollman, J. (1981). Formulation and application of a numerical scoring system for assessing histological activity in asymptomatic chronic active hepatitis. Hepatology, Vol.1, No.5, pp.431 - 435

Kock, N.G., Hahnloser, P., Roding, B. et al. (1972). Interaction between portal venous and hepatic arterial blood flow: an experimental study in the dog. Surgery, Vol.72, pp.414-419

Kumagi, T.\&Heathcote, E.J. (2008). Primary biliary cirrhosis. Orphanet Journal of Rare Diseases; 3:1. Doi: 10.1186/1750-1172-3-1

Kutlu, R., Karman, I., Akbulut, A. et al. (2002). Quantitative Doppler evaluation of the splenoportal venous system in various stages of cirrhosis: Differences between right and left portal veins. J Clin Ultrasound, Vol.30, pp.537-543

Lackner, C., Struber, G., Liegl, B., Leibl, S., Ofner, P., Bankuti, C., Baner, B. \& Stanber, R.E. (2005). Comparison and validation of simple noninvasive tests for predication of fibrosis in chronic hepatitis C. Hepatology, Vol.100, pp.868-873

Lafortune, M., Matricardi, Lm, Dens, A., Favret, M. et al. (1998). Segment 4 (quadrate lobe): barometer of cirrhotic liver disease at US. Radiology, Vol.206, pp.157-160

Lim, A.K.P., Patel, N., Eckersley, R.J. et al. (2005). Can Doppler sonography grade the severity of hepatic C-related liver disease? AJR, Vol.184, pp.1848-1853

Manning, D.S. \& Afdhal, N.H. (2008). Diagnosis and quantitation of fibrosis. Gastroenterology, Vol.134, pp.960-974

Matsui, O., Kadoya, M., Yoshikava, J. et al. (1995). Aberant gastric venous drainage in cirrhotic liver: Imaging findings in focal area of liver parenhima. Radiology, Vol.197, pp.345-34

Mehta, S.H., Lau, B., Afdol, N.H. \& Thomas, D.L. (2009). Exceeding the limits of liver histology markers. J. Hepatology, Vol.50, No.1, pp.36-41

Montano-Loza, A.J., Carpenter, H.A.\&Czaja, A.J. (2007). Consequences of treatment withdrawal in type 1 autoimmune hepatitis. Liver Int, Vol.27, No.4, pp.507 - 515

Needleman, L., Kurtz, A.B., Rifkin, M., Cooper, H.S. et al. (1986). Sonography of diffuse benign liver disease: accuracy of pattern recognition and grading. AJR, Vol.146, pp.1011-1015

Nishiura, T., Vatanabe, H., Matsuoka, Y et al. (2005). Ultrasound evaluation of fibrosis stage in chronic liver disease by simultaneous use of low and high frequency probes. The British J Radiology, Vol.78, No.927, pp.189-197 
O'Donohue, J., Chaan, N.G., Catnach, Ng.C. et al. (2004). Diagnostic value of Doppler assessment of the hepatic and portal vesels and ultrasound of the spleen in liver disease. Eur J Gastroenterol Hepatol, Vol.16, pp.147-155

Oo, Y.H., Hubscher, S.G., Adams, D.H. (2010). Autoimmune hepatitis: new paradigms in the pathogenesis, diagnosis, and management. Hepatol Int, Vol. 4, pp.475 - 493

Pierce, M.E.\&Sewell, R. (1990). Identification of hepatic cirrhosis by duplex Doppler ultrasound value of the hepatic artery resistive index. Australian Radiology, Vol.34, pp.331-333

Piscaglia, F., Gaiani, S., Zironi, G. et al. (1997). Intra and extrahepatic arterial resistances in chronic hepatitis and liver cirrhosis. Ultrasound Med Biol, Vol.23, pp.675-682

Poff, J.A., Coakley, F.V., Qayyum, A., Yeh, B.M. et al. (2008). Frequency and histopathologic basis of hepatic surface nodularity in patients with fulminant hepatic feilure. Radiology, Vol.249, pp.518-523

Poynard, T., Imbert-Bismut, F., Munteanu, M., Messous, D., Myers, R.P., Thabut, D., Ratziu, V., Mercadier, A., Benhamou, Y.\&Hainque, B. (2004). Overview of the diagnostic value of biochemical markers of liver fibrosis (FibroTest, HCV FibroSure) and necrosis (ActiTest) in patients with chronic hepatitis C. Comparative Hepatology, 3:8 doi:10.1186/1476-5926-3-8

Reed, J.C. (2000). Warner-Lambent/Parke-Davis awards lecture: mechanisms of apoptosis. Am. J. Pathol., Vol.157, pp.1415-1430

Reddy, K.R. \& Schiff, E.R. (2002). Sampling error and intraobserver variation in liver biopsy in patients with chronic HCV infection. Am. J. Gastroenterol., Vol.97, pp.2614-2618

Roobottom, C.A., Hunter, J.D., Westson, M.J. et al. (1995). Hepatic venous Doppler waveforms: changes in pregnancy. J Clin Ultrsound, Vol.23, pp.477-482

Rousselet, M.C., Michalak, S., Dupre, F., Croué, A., Bedossa, P., Saint-André, J.P. \& Cales, P. (2005). Sources of variability in histological scoring of chronic viral hepatitis. Hepatology, Vol.41, pp.257-264

Ryder SD and on behalf of the Trent Hepatitis C Study Group. (2004). Progression of hepatic fibrosis in patients with hepatitis C: a prospective repeat liver biopsy study. Gut, Vol.53, No.3, pp.451 - 455

Sacerdoti, D., Merkel, C., Bolognesi, M. et al. (1995). Hepatic arterial resistance in cirrhosis with and wihout portal vein trombosis: relationships with portal haemodynamics. Gastroenterology, Vol.108, pp.1152-1158

Schattenbeg, J.M., Galle, P.R. \& Schuchmann, M. (2006). Apoptosis in liver disease. Liver International, Vol.26, No.8, pp.904-911

Scheuer, P.J. (1991). Classification of chronic viral hepatitis: a need for reassessment. J Hepatol, 1991; Vol.13, No.3, pp. 372 - 374

Schinoni, M.I., Paraná, R. \& Cavalcante, D. (2006). Apoptosis and progression of hepatic fibrosis in hepatitis C patients. Braz. J. Infect. Dis., Vol.10, No.2, pp.117-121

Schneider, A.R.J., Teuber, G., Kriener, S.\&Caspary, W.F. (2005) Noninvasive asseessment of liver steatosis, fibrosis and inflamation in chronic hepatitis $\mathrm{C}$ virus infection. Liver international, Vol.25, pp.1150-1155

Shiha, G., Sarin, S.K., Ibrahim, A.E., Omata, M., Kumar, A., Lesmana, L.A., Leung, N., Tozun, N., Hamid, S., Jafri, W., Maruyama, H., Bedossa, P., Pinzani, M., Chawla, Y., Esmat, G., Doss, W., Elzanaty, T., Sakhuja, P., Nasr, A.M., Omar, A., Wai, C.T., Abdallah, A., Salama, M., Hamed, A., Yousry, A., Waked, I., Elsahar, M., Fateen, A., 
Mogawer, S., Hamdy, H., Elwakil, R. (2009). Liver fibrosis: consensus recommendations of the Asian Pacific Association for the study of the liver (APASL). Hepatol Int, Vol.3, pp.323 - 333

Silveira M.G.\&Lindor, K.D. (2008). Primary sclerosing cholangitis. Can J Gastroenterol, Vol.22, No.8, pp689 - 698

Silveira, M.G.\&Lindor KD. (2008). Clinical features and management of primary sclerosing cholangitis. World J Gastroenterol, Vol.14, No.2, pp.3338 - 3349

Skripenova, S., Trainer, T.D., Krawitt, E.L.\&Blaszyk, E. (2007). Variability of grade and stage in simultaneously paired liver biopsies in patients with hepatitis C. J Clin Pathol, Vol.60, pp.321 - 324. Doi: 10.1136/jcp2005.036020

Standish, R.A., Cholongitas, E., Dhillon, A., Burroughs, A.K.\&Dhillon, A.P. (2006). An appraisal of the histopatological assessment of liver fibrosis. Gut, Vol.55, pp.569 578

Suzuki, A., Mendes, F. \& Lindor, K. (2005). Diagnostic model of esophageal varices in alcoholic liver disease. Eur. J. Gastroenterol. Hepatol., Vol.17, No.3, pp.307-309

Taourel, P., Blanc, P., Dauzat, M., Pradel, J. et al. (1998). Doppler study of mesenteric, hepatic and portal circulation in alcoholic cirrhosis: relationship between quantitative Doppler measurements and severity of portal hypertension and liver failure. Hepatology, Vol.28, pp.932-936

Techgraber, U.K., Gebel, M., Benter, T. et al. (1997). Effect of respiration exercises and food intake on hepatic vein circulation. J Ultrasound Med, Vol.16, pp.549-554

Totty, B.A. (2002). In: Theory and practice of histological techniques, 5th ed. Bancroft, J.D.\&Gamble (Eds.), 163-200, M. Churchill Livingstone, Edinburgh (International edition)

Vigano, M., Visentin, S., Aghemo, M. et al. (2005). US features of liver surface nodularity as a predictor of severe fibrosis in chronic hepatitis C. Radiology, Vol.234, pp.641

Vilgrain, V. (2001). Ultrasound of diffuse liver disease and portal hypertension. Eur Radiology, Vol.11, pp.1563-77

von Birbra, H., Schober, K., Jenni, R. et al. (1989). Diagnosis of constrictive pericarditis by pulsed Doppler echocardiography of hepatic vein. Am J Cardiol, Vol.63, pp.483-488

von Herbay, A., Frieling, T. et al. (2001). Association between duplex Doppler sonographic flow pattern in right hepatic vein and various liver diseases. J Clin Ultrasound, Vol.29, pp.25-30

Walsh, K.M., Leen, E., Mac Sween, R.N. et al. (1998). Hepatic blood flow changes in chronic hepatitis $\mathrm{C}$ measured by duplex Doppler color sonography: relationship to histological features. Dig Dis Sci, Vol.43, No.12, pp.2584-90

Yokoyama, S.C., Finegold, M.J., Sturniolo, G.C., Kim, K., Mescoli, C., Rugge, M.\&Medici, V. (2010). Wilson disease: histopathological correlations with treatment on follow-up liver biopsies. World J Gastroenterol, Vol.16, No.12, pp.1487 - 1494

Zironi, G., Gaiani, S., Fenyves, D., Rigamonti, A., Bolondi, L. et al. (1992). Value of measurement of mean portal flow velocity by Doppler flowmetry in the diagnosis of portal hypertension. J of Hepatology, Vol.16, pp.298-303

Zwiebel, W.\&Pellerito, J.S. (2005). Introduction to vascular ultrasound. Elsevier Suonders. 5th ed. pp.585-590 


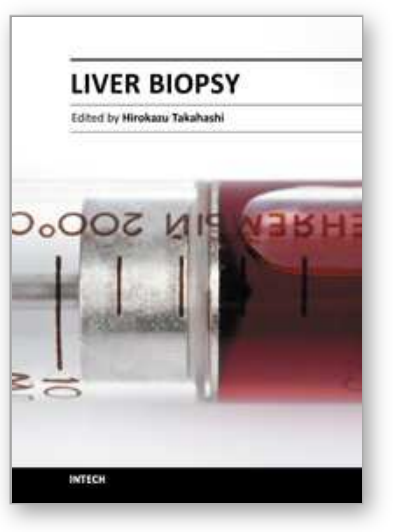

\author{
Liver Biopsy \\ Edited by Dr Hirokazu Takahashi
}

ISBN 978-953-307-644-7

Hard cover, 404 pages

Publisher InTech

Published online 06, September, 2011

Published in print edition September, 2011

Liver biopsy is recommended as the gold standard method to determine diagnosis, fibrosis staging, prognosis and therapeutic indications in patients with chronic liver disease. However, liver biopsy is an invasive procedure with a risk of complications which can be serious. This book provides the management of the complications in liver biopsy. Additionally, this book provides also the references for the new technology of liver biopsy including the non-invasive elastography, imaging methods and blood panels which could be the alternatives to liver biopsy. The non-invasive methods, especially the elastography, which is the new procedure in hot topics, which were frequently reported in these years. In this book, the professionals of elastography show the mechanism, availability and how to use this technology in a clinical field of elastography. The comprehension of elastography could be a great help for better dealing and for understanding of liver biopsy.

\title{
How to reference
}

In order to correctly reference this scholarly work, feel free to copy and paste the following:

Ludmila Viksna, Valentina Sondore, Jāzeps Keiss, Agita Jeruma, Pēteris Prieditis, Ilze Strumfa, Arturs Sochnevs and Baiba Rozentale (2011). Noninvasive Alternatives to Liver Biopsy, Liver Biopsy, Dr Hirokazu Takahashi (Ed.), ISBN: 978-953-307-644-7, InTech, Available from: http://www.intechopen.com/books/liverbiopsy/noninvasive-alternatives-to-liver-biopsy

\section{INTECH}

open science | open minds

\section{InTech Europe}

University Campus STeP Ri

Slavka Krautzeka 83/A

51000 Rijeka, Croatia

Phone: +385 (51) 770447

Fax: +385 (51) 686166

www.intechopen.com

\section{InTech China}

Unit 405, Office Block, Hotel Equatorial Shanghai

No.65, Yan An Road (West), Shanghai, 200040, China

中国上海市延安西路65号上海国际贵都大饭店办公楼 405 单元

Phone: +86-21-62489820

Fax: $+86-21-62489821$ 
(C) 2011 The Author(s). Licensee IntechOpen. This chapter is distributed under the terms of the Creative Commons Attribution-NonCommercialShareAlike-3.0 License, which permits use, distribution and reproduction for non-commercial purposes, provided the original is properly cited and derivative works building on this content are distributed under the same license. 